\section{Methods of Treatment}

A study of end-results shows that some cases of varicose veins may be adequately dealt with by injection alone, others by combined injection and ligation, and still others by limited excisions. Choice of treatment must be determined by the particular group of case to which the patient belongs. It is therefore necessary to decide which patients are best suited for each of these particular varieties of treatment-namely, injection, injection with ligation, or excision.

Injection.-This method is suitable for relatively small and comparatively isolated varices such as are so commonly seen in young and middle-aged women. For the injection many different sclerosing agents have been used, but in 1937 H. I. Biegeleisen of New York drew attention to mono-ethanolamine oleate, claiming that it was less ioxic and a better sclerosing agent than sodium morrhuate and that, being, in contradistinction to morrhuate, a definite chemical compound, it could be prepared in perfectly comparable batches. In Cardiff we have verified Biegeleisen's contention, and are now using mono-ethanolamine oleate, $\mathrm{C}_{1 ;} \mathrm{H}_{33} \mathrm{COONH}_{3} \mathrm{CH}_{2} \mathrm{CH}_{2} \mathrm{OH}$. This is a deliquescent solid, which is made into a 5 per cent. solution that is, slightly turbid; although it may safely be employed in this form it is better clarified by the addition of 25 per cent. glycerin or 2 per cent. benzyl alcohol. Five c.cm. or more may be used at weekly intervals. A firm thrombus is formed, and this solution is, in our opinion, the most satisfactory of the sclerosing agents. Morrhuate and quinine urethane solutions have their contraindications, while salicylates tend to be painful. None of these disadvantages attends the use of the oleate solution, and as it is only slightly irritant to the perivenous tissues, ulceration is not likely to occur if a little escapes through the puncture in the vein.

Ligation.-Where Trendelenburg's test is positive in the type of case already referred to, in which the great saphenous venous trunk is chiefly affected, ligation of the termination of the trunk by fine silk or catgut suture is combined with injection of the outstanding varicose clusters. The descending thrombosis which follows the ligation greatly reduces the number of veins that require to be treated by injection, and the removal of the hydrostatic pressure from above renders the injections more effective. At the same time the advantages of an ambulatory form of treatment are preserved, since the ligation as well as the injection treatment is carried out under local analgesia. Emphasis has already been laid on the necessity for tying the internal saphenous vein at the saphenous opening above its highest tributary-that is, immediately before its termination in the femoral vein. It is also advisable, after ligating and dividing the vein between ligatures, to transfix the short segment of vein beyond each ligature and again tie the ligatures so as to make sure of their not slipping. This is particularly important in a patient who is allowed to walk about. It is as well not to transfix the upper segment of the vein proximal to the ligature lest thrombus form around the transfixion suture and extend into the femoral vein, where it may conceivably be detached and give rise to pulmonary embolism or infarction-a complication which we have fortunately never seen in connexion with the treatment discussed.

Excision.-The great majority of varicose veins can be satisfactorily treated either by injection alone or by injection with ligation; a small group remain which may require further ligations-for example, of the external saphenous vein, or a more distal ligature in the case of the internal saphenous in addition to the terminal ligature already described. Some few remain that are best treated by excision: such are cases of large isolated and distended knots occurring in young people and of ten apparently not directly connected with either saphenous system. These are comparatively rare.

\section{Conclusion}

With the great increase in the popularity of sclerosing solutions in recent times the more surgical methods of treatment have become somewhat neglected, but a study of the number of failures resulting from injection alone has shown that the best treatment of varicose veins is only occasionally injection, ligation, or excision, each practised as an independent measure. Most cases are best treated by a combination of injection and ligation.

\section{Summary}

The aetiology of varicose veins is surveyed, congenital and congestive influences being considered prominent factors.

Varicocele is a transient condition and should be treated conservatively.

Recurrences after treatment of the leg veins, and new varices incorrectly regarded as recurrences, are discussed.

It is contended that most cases are best treated by combined ligation and injection, particularly where Trendelenburg's test is positive.

The preparation and advantages of ethanolamine oleate solutions as sclerosing agents are discussed.

REFERENCE

Biegeleisen, H. I. (1937). Ann. Surg., 105, 610

\section{NERVOUS DISORDER AFTER INJURY}

\section{A REVIEW OF 400 CASES}

BY

\section{JEFFREY RAMSAY, O.B.E., M.D., F.R.C.P. Blackburn}

A distinguished judge is reported recently to have stated that he regarded workmen's compensation as far and away the most difficult branch of the law, and he added that one of the chief difficulties in all these cases was traumatic neurasthenia. The medical aspect of the Workmen's Compensation Act presents many problems, particularly in the nomenclature and classification of the various functional nervous disorders which may be associated with injury. To label such disorders with the general heading "traumatic neurasthenia" is to ignore modern psychological approach and to stultify prognosis and treatment. One of the objects of this review is to call attention to the confusion which appears to exist in this respect and to put forward certain suggestions for classification. I write as a general physician who has been interested in such cases for the past twenty-five years, and not as a specialist in psychiatry.

There are two aspects of any injury. First, there is the surgical aspect, which deals with the anatomical disturbance caused by such injury, and its local effect: of the series under review 235 , or 59 per cent., come into this category. Secondly, there is the result of the injury on the patient's nervous system. By this I do not imply organic injury to nerves, but a functional or psychogenic reaction which may lead to distortion or exaggeration of 
the local effect and to other and more remote symptoms. In this series 165 cases, or 41 per cent., show such functional nervous disorder as a sequel to accident. Particularly in cases which reach a court of law, this latter manifestation is an important one. In fact, it is not infrequently the major issue before the court. Union may be perfect after a fractured thigh, but loss of morale may prevent a man from attempting to scale a ladder again. Let us suppose that two individuals, of approximately the same age and physique, sustain a similar injury. One of the two makes an uneventful recovery and is soon back at work; the other develops functional nervous symptoms which may entail lengthy litigation and prolonged absence from occupation.

\section{Factors which Might Contribute to Functional Nervous Disorder}

The 400 cases have all been examined by me within the last three years. They are taken seriatim from my case-books and have not been selected in any way. That is to say, the vast majority were referred to me solely because I was known to be interested in this type of medico-legal work and not because a physician's opinion was required in reference to the nervous system. Many of the cases showed some comparatively trivial injury, without any other disturbance whatever. I propose, with the help of full notes taken on each case at the time, to investigate certain aspects which might be supposed to have a bearing on functional nervous disorder after the initial injury.

(a) Age.-It might be thought that increasing age would lead to an increased tendency towards psychological sequelae. The job has perhaps been a monotonous one, followed conscientiously for many years until the individual is weary of it and his tissues are on the down grade. The accident might well provide a subconscious escape. I am quite sure that such mechanism does come into play at times. On the other hand it might be argued that in a younger person the shock of any accident, with an effect which may be maiming or disfiguring, might well be greater than in someone who is older. The actual figures show that the average age of the patient who shows no nervous sequelae is 39 , whereas in those showing such disorder it is 41 . There is no appreciable difference in these figures.

(b) Sex.-The first group, showing no psychological disorder, contains 69 per cent. of males and 31 per cent. of females. The second group, showing functional nervous disorder after the injury, contains 55 per cent. of males and 45 per cent. of females. This difference, 14 per cent., is not very great. (All percentages throughout this paper are given to the nearest decimal point.)

(c) Severity of Injury.-Does the severity of the injury bear any relation to subsequent psychological disorder? The cases in this series of 400 may be classified broadly as follows: fractures 113 , amputations 18 , concussions, 38 , dislocations 7 , contusions and sprains 112, sepsis (fingers, etc.) 14, cuts and abrasions 67, and a miscellaneous group (dermatitis, hernia, carbon monoxide poisoning, etc.) 31 . Although it is obvious that there may be exceptions to the rule, it is safe to say that the average fracture is likely to be a more serious injury than the average contusion or sprain. Therefore I propose to take these two classes as representing respectively a more serious and a less serious type of injury. It will be noticed that the numbers in the two classes are approximately equal. Among the frarture cases 63 per cent. showed no func- tional nervous disorder, and in the remaining 37 per cent. functional nervous disorder was present. Among the contusions and sprains 46 per cent. showed no functional nervous disorder, and in the remaining 54 per cent. functional nervous disorder was present. The numbers in each series are too small to enable any far-reaching conclusion to be drawn, but the results certainly suggest that. the severity of the injury does not predispose to subsequent development of functional nervous disorder.

\section{The Psychological Factor}

There must be some explanation for the fact that 41 per cent. of the cases in this series developed functional nervous disorder as a sequel to injury. But this apparently high figure becomes less surprising when we consider the incidence of functional (as opposed to organic) disease in ordinary medical practice at the present time. Sir Walter Langdon-Brown (1938) questioned various general practitioners as to what proportion of their patients suffered from functional rather than organic disease; not one of these doctors placed the figure at less than 40 per cent., while some put it as high as 75 per cent. Dunbar, Wolfe, and Rioch (1936) say that the figure ranges from 35 to 75 per cent., but they observe that this number must of necessity be arrived at on the basis of impression rather than of careful determination. Seeing that such a large proportion of ordinary illness is regarded as being of functional type, it is no wonder that the figure is also high when there is an added "psychosomatic interaction" associated with injury.

There seems no reason to doubt that in such cases the soil is ready for the seed; in other words, that some mental conflict or maladjustment to life was already present and that the injury acted as an exciting cause of the psychoneurotic symptoms which developed subsequently. Suggestion in such individuals is a potent factor. They are usually more prone to suggestion than are their more fortunate fellows who show no nervous phenomena. Autosuggestion may be rational or irrational. Fear may have been engendered at the moment of the accident and may persist after the actual effects of the accident might be expected to have worn off. Autosuggestion may perpetuate lack of function in a limb which has been injured. There may be a sense of resentment: the injured person feels that someone must be made to pay adequately for all that he has undergone. This is the basis of the German name "justice neurosis" for what we call "compensation neurosis." Even if the accident has been due to his own carelessness or negligence the mental mechanism of projection may come into play and enable him to fix the blame on to someone else. Then there is the ever-present fear that the accident has been or will be the cause of losing his place at work. This is a very real source of anxiety. An especially difficult case is that of the man who has been in temporary employment, which has now ceased automatically apart from his accident. In my experience such men are particularly liable to exaggerate their symptoms: in the circumstances there is a great temptation to do so. Suggestion by others is equally potent: the man's friends sympathize with his sufferings and tell him that he deserves ample remuneration; they may remind the patient of other workmen who have been similarly injured. An incautious remark from a doctor as to the apparent severity of the case may act as a powerful suggestion of this kind.

The individual's life develops along certain lines. In an environment which is as near to the ideal as possible 
there is comparatively little stress and conflict, but such an environment is the exception rather than the rule, and the psychoneuroses of adult life result from early emotional conflicts. The individual who recovers from an injury with little or no psychic disorder as a sequel has presumably developed without much emotional disturbance, whereas the man who shows functional nervous sequelae is he in whom, as I have said, the soil is ready for the seed. Such a man will say, and will believe the statement to be perfectly true: "I was all right until the accident, and look at me now." As a matter of fact he was, from a psychological standpoint, far from all right before his injury; the latter has merely brought to light his pre-existing intrapsychic difficulties.

There is nothing new in the views expressed above. They were found to be true in connexion with the psychoneuroses which were seen in the war of 1914-18, and the work of the last twenty years has, in my opinion, confirmed them beyond all reasonable doubt.

\section{Classification of the Neuroses following Injury}

A psychoneurosis may be defined as a result arising from incomplete solution of a mental conflict. I suggest the following classification for the 165 cases in this series which showed functional nervous disorder:

(a) Post-concussion syndrome

(b) Hysteria

(c) Neurasthenia

(d) Anxiety state

$\begin{array}{rrrrrrr}\ldots & 38 & \text { cases, or } & 23 & \text { per cent. } \\ \ldots & 102 & . & , & 62 & . & , \\ . & 16 & . & , & 10 & , & , \\ \ldots & 9 & , & , & 5 & , & ,\end{array}$

This classification is intended merely as a working basis for the elucidation of signs and symptoms and hence as a guide towards prognosis and treatment. In no sense is it meant to imply that the neuroses following injury can be fitted into four or more watertight compartments. Such an arrangement would not be feasible, because it is obvious that there may be considerable overlapping: an individual may show evidence of more than one of the above disorders.

For medico-legal work any attempted classification should be a straightforward one ; each term which is used should be capable of clear definition and of explanation in simple language. It is better to avoid, if possible, the discussion of such matters as phobias, obsessions, and neuropathic inheritance. It will be noted that, with the exception of the post-concussion syndrome, which has an organic basis, the classification deals only with so-called functional disorders: space prevents me from touching upon such organic troubles as disseminated sclerosis or cerebral tumour following injury. Valuable information in this connexion can be found in a book by W. A. Brend (1938).

\section{Post-concussion Syndrome}

The word "concussion" is apt to be used loosely. Dorland defines cerebral concussion as " a condition caused by violent blows upon the head, attended with vertigo, loss of consciousness, nausea, weak pulse, and slow respiration." Professor Wilfred Trotter has defined concussion as "an essentially transient state due to head injury, which is of instantaneous onset, manifests widespread symptoms of a purely paralytic kind, does not as such comprise any evidence of structural cerebral injury, and is always followed by amnesia for the actual moment of the accident." It is very difficult at times to distinguish between a severe concussion and a (perhaps mild degree of) cerebral contusion or laceration. Indeed; there seems to be no reason why the conditions may not coexist. Purves-Stewart states that the post-concussion syndrome shows a characteristic group of chronic symp- toms which may last for months or even years, and which are due to traumatic meningo-encephalitis with haemorrhages and minute lacerations of the brain or pia arachnoid. It is sometimes difficult in such cases to differentiate between primary psychological and secondary psychological and neurological sequelae. The postconcussion syndrome may show a large overlap in its symptomatology with the picture in an acute exacerbation of a chronic anxiety state-in fact, the clinical picture may be more that of an anxiety state, coloured by symptoms and signs of concussion, rather than the reverse.

Diagnosis.-The history of the accident points to concussion. The most important symptom is headache, which usually comes on when the patient gets up in the morning, and which is made worse by postural changes or by coughing. The memory as a rule is unimpaired, but there is usually some degree of mental inertia and lack of power of concentration. The patient is generally oversensitive to loud sounds and bright lights; dizziness is a common symptom, and there may be some change in personality, with irritability and emotionalism. Such patients are intolerant to alcohol: a much smaller dose than usual tends to produce intoxication. Tremors are frequent; sleep is apt to be disturbed.

Example.-Mrs. A., aged 52, housewife, was a passenger in a saloon motor-car which was involved in a collision with another vehicle. She remembered nothing of the accident, and regained consciousness after admission to hospital, where a diagnosis of cerebral concussion was made. $X$-ray examination of the skull showed no evidence of fracture. When seen six months after the accident she was complaining of headache and of dizziness, occurring chiefly when she changed her position. Apart from a scar on the chin there were no signs of injury. She was found to be unsteady if she made any sudden movement or if she stood with the eyes closed. No evidence of any organic lesion of the nervous system could be elicited by examination.

\section{Hysteria}

The word "hysteria" is capable of two interpretations. There is the popular conception, which implies a blend of imaginary symptoms with an early Victorian atmosphere of "the vapours": hence there may be a faint stigma attached to the word. "Traumatic neurasthenia" sounds much more imposing and face-saving, even if it is entirely incorrect as a diagnosis. Dorland defines hysteria as "a disease characterized by lack of control over acts and emotions, by morbid self-consciousness, by exaggeration of the effect of sensory impressions, and by simulation of various disorders." Two chief varieties of hysteria are recognized by psychologists-conversion hysteria and anxiety hysteria. The definition given above is really that of the latter disorder. Conversion hysteria, when it shows belle indifference to the symptom, does not fit easily into this definition. The absence of open emotion is the main pitfall in diagnosis from the physician's point of view. Without going into the many theories which have been put forward in explanation of this condition-the names of Freud, Janet, and Babinski are associated with these-it may be sufficient to say that hysteria is characterized by heightened suggestibility, and as suggestion plays a considerable part in the sequelae of an injury it is not surprising that hysteria is one of the commonest varieties of functional nervous disorders after such injury.

Diagnosis.-The patient becomes egocentric; he craves for sympathy either openly or by more devious ways; he is introspective and his emotional control tends to be enfeebled. There may be aphasia, aphonia, anosmia, 
alleged defects of vision, and excessive volubility. Hysterical pains may be referred to any part of the body: headache, particularly in the occipital region, is common, as is spinal pain and limited movement, especially following local trauma in this region. Passive movement may be resisted strenuously and may be accompanied by emotional deep breathing. Clonic spasms or tremors may affect one limb only, which would be an unusual manifestation in organic disease; hysterical paralysis may be flaccid or accompanied by contracture. Tachycardia with precordial discomfort, in the absence of evidence of organic heart disease after adequate investigation, is a common symptom. Other manifestations are rapid breathing, cough (again without discoverable reasons for it), aerophagy, dysphagia, globus hystericus, vomiting, anorexia, meteorism, constipation, diarrhoea, and pyrexia. Tendon reflexes tend to be normal or exaggerated, and during their elicitation the patient may complain of great discomfort. The tendon reflexes are never lost in pure hysteria (Purves-Stewart). The plantar response is flexor in type. Although the nature of the symptoms may be highly suggestive of a hysterical origin, every care should be taken to exclude organic disease. For this purpose clinical observation and experience are the essentials; valuable confirmatory evidence can be obtained from electrical reactions, radiology, biochemistry, and other ancillary sources.

Example.-A man aged 52, shop assistant, while walking on the pavement, was struck in the back by a motor lorry; he did not lose consciousness, and continued his journey by tram-car. There was some bruising of the back but no $x$-ray evidence of injury. Almost immediately after his accident he began to have attacks of palpitation on slight exertion or excitement. When seen three months after the accident no residual effects of the injury could be detected, but the patient was worried by wondering if the heart condition had resulted from the accident and if the former were serious. The heart was examined clinically, electrocardiographically, and by means of Master's staircase test, and its condition was found to be entirely normal. The tachycardia was evidently of nervous origin, following his minor accident.

\section{Neurasthenia}

Dorland's definition of neurasthenia is " nervous prostration; a nervous disorder characterized by abnormal fatigability." I do not think that modern psychology would quarrel with this definition. Predisposing factors may be sexual excesses, prolonged mental or physical overstrain, and toxic foci. Eye-strain may be present. Some of these cases may be in reality severe anxiety states in which the energy of the individual is used up in suppression and repression. Other cases, diagnosed as neurasthenia in the first instance, prove on fuller investigation to be anxiety states in shut-in and schizoid personality types. In these the prognosis is correspondingly poor. From the figures which have been given above it will be seen that true neurasthenia is a comparatively rare functional nervous disorder after injury.

Diagnosis.-The cardinal feature is undue fatigability: The patient is too tired to make any exertion; sometimes too fatigued even to eat in a normal manner. There is lack of concentration power; the memory is unimpaired and the patient relates his woes at great length; he is usually full of aches and pains, and he may be depressed and emotional. On the physical side the blood pressure is usually low, and there may be a wide difference in the pulse rate when the patient is standing up and when he is lying down. Transient blotches of redness on the sides of the neck are common. Abdominal discomfort is frequent. The reflexes are generally lively; the kneejerk tends to be brisk.

Example.-Mrs. B., aged 47, housewife, was involved in a collision when travelling as a passenger in a motor-car. She sustained superficial cuts and bruising, but there was no $x$-ray evidence of fracture. When she was examined six weeks after the accident she complained that her nerves were upset and that her thighs would not support her when she rose. from a sitting position; she felt shaky after standing for a few moments, and was quite unable to do more than a small portion of her household duties. She was depressed and emotional, and spoke at great length of her lack of energy and power for work. An obvious potential focus of infection was the presence of many decayed teeth in the lower jaw. Beyond two small scars on the forehead and nose, no evidence of injury was found. There was tremor of the outstretched arms and of the closed eyelids.

\section{Anxiety State}

In this manifestation the patient shows paroxysms of terror and emotional anguish. The condition is thought to be due to repression of antecedent emotional strain in a neuropathic temperament.

Diagnosis.-In addition to the emotional paroxysms which have been mentioned, the patient complains of broken sleep and of nightmares, in which scenes of terror are revived; these may be particularly associated with the accident. Tremors and palpitation are usual.

Example.-A man aged 62, labourer, was kicked in the testicle by a bullock and was in bed for six weeks following the injury. Before this incident he had had no illness and had been following his occupation in apparently good health. When examined about three months after the accident the left testicle was found to be enlarged and tender, and the condition was considered to be a haematocele; this was apparently improving steadily. He had been married for the second time six months before his injury. He was in a state of extreme depression, complaining of broken sleep, general nervousness, and attacks of fainting, with shooting pains across the shoulders. He hinted that he had contemplated suicide. His blood pressure was $250 / 175$; there was tremor of the tongue, the closed eyelids, and the outstretched arms. Treatment by a psychiatrist at a clinic was advised. He has improved a little, but is now (nearly two years after his accident) still unfit for work on account of his nervous condition.

Before leaving this section I should like to say that in my opinion true malingering is rare in compensation cases. "There may be a mild degree of "lead-swinging" in certain individuals, but deliberate attempts at deception appear to me to be infrequent. The term "compensation neurosis" is one which I dislike-to me it implies a suggestion of malingering for purposes of gain. While it may be true that a man is quite willing, or even rather overwilling, to make the most of his disability in certain circumstances, I consider that a suggestion of compensation neurosis is not often justifiable. A word must be said with regard to "brooding," a condition which is recognized in law in that it may cause incapacity for work and may not necessarily be the result of the accident.

\section{Prognosis}

Prognosis-the future outlook-is the crux of the medico-legal problem in compensation cases. In order that it may arrive at a just decision, the court expects medical witnesses to give a careful and reasoned opinion as to the individual's prospects of future health and usefulness.

In post-concussion syndrome the headache may last for months or even years. In my view it is unwise to 
express any definite opinion as to the length of time during which the headache may persist. Brend gives it as his experience that the symptoms usually clear up in a few months to a year, and that if they are prolonged much beyond that period investigation will probably show that the symptoms are being maintained by. other factors. It does not follow that an individual is unfit for any work because there is still a complaint of headache. In hysteria the prognosis is favourable if the principles of treatment are thoroughly understood, because the heightened suggestibility of the individual can be utilized to suggest improvement and cure. In my opinion the prognosis in this class of case is better than in either of the other three classes. Each case must be considered on its merits as regards the length of time that is likely to elapse before relief can be expected. In neurasthenia and anxiety neurosis the prognosis after injury is not quite so favourable: more time and more patience are usually needed, though the ultimate result is often satisfactory.

\section{Treatment}

Before discussing the treatment of functional nervous disorders after injury it is advisable to refer briefly to certain factors which may help to prevent the development of such disorders. At Blackburn Royal Infirmary we have a most efficient fracture clinic, and the personality of the surgeons who are in charge goes a long way towards preventing the development of psychoneuruses. The establishment of a complete service of such fracture clinics throughout the country, each one under the control of a surgeon who will take into consideration the patient as a whole and not confine his attention solely to the injury, will help to lessen nervous sequelae. Optimism to a justifiable extent, openly expressed, rather than silence and an implied or stated pessimism, should be the rule. The patient's own medical adviser should adopt this attitude, and even the doctor who examines the case when litigation is pending can at times be a help to the patient in this respect.

In the treatment of cerebral concussion the patient should rest in bed for at least a fortnight after the injury, even in the mildest case. Physical and mental rest play an important part in the treatment of post-concussion syndrome, which is probably related, in fact, to manifest pathological changes. Hysteria, neurasthenia, and anxiety neurosis may all require a certain degree of mental exploration-a term which is tending to supplant the misuse of the term "psycho-analysis"-in the course of their treatment, followed by persuasion and suggestion. In my opinion the best method of treating such cases is to admit them to a general hospital under the care of a physician who is interested in psychology. Here the case can be investigated thoroughly from every angle, physical and psychical. I think it is better to have these cases in a general ward; if they are segregated with psychoneurotics there is a tendency to compare notes, and the result is not always favourable. The more severe type of case may require mental exploration by an expert.

Is the financial settlement of a claim useful as an auxiliary method of treatment, so to speak? I think that it would be safe to say that it often helps in this direction, and in some instances the results are dramatic. I have in mind one case which resembled the worst type of post-war neurosis-general tremors which literally shook the floor when the patient was sitting in a chair, and a painfully evident emotionalism. The outlook with reference to ultimate fitness for work seemed bad in this case. The man received several hundreds of pounds in compensation: whether post hoc or propter hoc, he was back at full work within twelve months. A financial settlement places the responsibility for recovery on to the patient himself. Suitable light work may undoubtedly have a beneficial effect in assisting recovery in certain cases, by taking a man's mind off his injury and by making him feel that he is beginning to be worth while once again: this applies especially to cases in which depression is an outstanding feature. Finally, it might be argued that lack of sympathy and understanding (which must be distinguished from "spoiling") by employers, relatives, and doctors may be one of the main factors in producing post-traumatic psychological disorders. Whether this be true or not, it is at least incumbent upon us as doctors, in treating such cases, to let the patient see that we accord full recognition to his symptoms, even where they are of emotional origin.

\section{The Legal Aspect}

Before concluding I should like to deal with certain points in compensation cases which are not, strictly speaking, relevant to the title of the paper, but which may not be out of place. It is hardly necessary to stress the fact that any medical report which is asked for by a solicitor or insurance company, in a compensation case, may form the basis for a searching cross-examination by counsel in subsequent legal proceedings. Therefore such reports should be drawn up with the utmost care and no word should be used without due thought. A full history of the medical aspect of the case should be taken, but it is no part of the duty of a medical examiner to inquire into purely legal points-for example, as to the relative position of two vehicles which have collided. The patient's account of all his symptoms should be noted in full, and any dates and times should be as accurate as possible. During this account a preliminary impression of the patient is often formed by an experienced examiner. Apart from a detailed description of his injuries, it is essential to make a thorough general examination of the patient: the importance of finding, for example, sugar in the urine need only be mentioned to be appreciated. Further, the patient's expectation of life, so far as this can reasonably be estimated, may be of considerable moment in the case.

After the report has been furnished it is quite probable that the writer of it may have to give evidence in court in support of his opinion. If a technical expression must be used, an explanation should be added. After an experience of a quarter of a century, I should like to pay a warm tribute to Bench and Bar for the manner in which compensation cases are conducted; many of such cases are complicated and highly technical, and I have always been impressed with the patience, thoroughness, and complete impartiality which are shown throughout. It is the part of a medical witness to help the court in arriving at a just decision. A doctor should never be an advocate in the case. It is his business to give an unbiased account of his findings and to avoid a tendency to take sides. This is not to say that he may not have strong opinions in one direction as a result of his investigation of the case. But he should always be willing to concede any point in cross-examination when he can do so truthfully and conscientiously. Nothing is gained by an obstinacy which comes perilously near to advocacy. Judge and counsel see through evidence of this type immediately, and it may even tend to discredit the value of the remainder of the witness's statements. The criterion 
which one may well adopt is this: Could I make that assertion before a board of medical examiners if my qualifying diploma depended upon it? Viewed from this standpoint, I am afraid that I should have been forced to plough a medical witness occasionally if I had been one of the examiners. When expressing an opinion in the witness-box the word "probable" should be used in preference to " possible." Almost anything is possible, but the court wishes for information on reasonable probability.

Evidence should be given in a voice which can be heard. In the county of Lancaster a speaker, to be considered adequate, must "stand up, speak up, and then shut up," and the same principle should apply to the courts. A witness must perforce stand up (unless prevented by physical disability), and he should certainly speak up. I have seen a calm court change quickly into a life-like representation of William Henley's " place of wrath and tears" because a medical witness would insist on muttering unintelligible technicalities in an inaudible tone. If we have anything to say which is worth hearing, let it be heard. The third point in the adequate speechnamely, a knowledge of when to stop-is equally important. In other words, simple affirmative or negative replies to questions are desirable whenever possible, though at times it is necessary to add some such words as these: "I should, however, like to qualify this by saying. ..." Any witness who makes a long and rambling reply to a question is laying up trouble for himself and his case.

I think that no one will deny that there is a psychological background for the nervous disorders which may follow injury. Can we, as medical witnesses, hope to make such an approach intelligible in plain language when we are giving evidence? I can imagine the most urbane of His Majesty's judges dealing forcefully with a doctor who attempted to harangue the court on the relative merits of various schools of thought in psychology. But it is surely possible to explain that the mental make-up of the individual, and the influences which have been active since his earliest days, have had an effect on his outlook as regards his injury. Such a statement could only be regarded as sound common sense, but the viewpoint is one which has been in the past, and frequently still is, insufficiently stressed.

\section{Summary}

A series of 400 compensation cases is reviewed, and the proportion of those in which functional nervous disorder developed subsequently is given.

Factors in the causation of these disorders are discussed, and a classification of such disorders is put forward.

Views are expressed on prognosis and treatment in these cases.

The paper refers, in conclusion, to the legal aspect from the standpoint of the medical witness.

I wish to acknowledge with gratitude my indebtedness to Sir James Purves-Stewart's well-known book, The Diagnosis of Nervous Diseases, from which many quotations have been made in this paper.

\section{REFERENCES}

Brend, W. A. (1938). Traumatic Mental Disorders in Courts of Law, London.

Dunbar, H. F., Wolfe, T. P., and Rioch, J. M. (1936). Amer. J. Psychiat., 93, 649.

Langdon-Brown, Sir W. (1938). Thus we are Men, p. 105, London.

\section{THE STRUCTURE AND FUNCTIONS OF SYNOVIAL MEMBRANE AND ARTICULAR CARTILAGE*}

\author{
BY
}

A. G. TIMBRELL FISHER, M.C., F.R.C.S.

Honorary Orthopaedic Surgeon, St. John Clinic and Institute of Physical Medicine; Orthopaedic Surgeon to the Arthritic Unit, St. Stephen's Hospital (L.C.C.)

John Hunter taught us the need for accurate anatomical and physiological knowledge as a basis for the rational treatment of injury and disease. The result of neglect of this principle is demonstrated by the present unsatisfactory position relating to rheumatic diseases, particularly as they affect the joints. It has been estimated that in the United Kingdom alone there are more than a million adults and more than 200,000 children who are suffering from rheumatic disease, both articular and nonarticular, and it is probable that this number exceeds the combined total of those suffering from heart disease, tuberculosis, and cancer. These disturbing facts should stimulate further interest in the neglected subject of the anatomy and physiology of joints and of other structures liable to be attacked by rheumatism. In fact, we must replace the shifting sands upon which much of our treatment of rheumatism is at present based by a firmer foundation built upon Hunterian principles. Such principles are also of vital importance in the treatment of injuries of joints, if prolonged or even permanent disability is to be avoided and the menace of unqualified practice in this sphere removed.

It is impossible within the scope of a short paper to deal adequately with such a large subject, and as a basis of discussion I propose to discuss these problems under two principal headings: (a) the structure and functions of synovial membrane; (b) the structure and functions of articular cartilage.

\section{Structure and Functions of Synovial Membrane}

During the development of a diarthrodial joint a splitting of the undifferentiated mesenchyme occurs, the central part becoming the articular cartilages and interarticular fibrocartilages when present, and the lateral portion the synovial membrane, capsule, and its accessory ligaments. This mesenchymatous origin of the different elements of the joint explains the readiness with which under certain conditions, as in osteo-arthritis, cartilage and bone develop in the synovial membrane, or with which the articular cartilage and interarticular cartilages may be transformed into connective tissue or bone. It was formerly considered that the synovial membrane of a joint forms a closed sac which completely covers the inner surface of the capsule and the surfaces of the articular cartilages. It is now established, however, that the synovial membrane resembles rather a sleeve with two surfaces and two circumferences, the latter being attached to the margins of the articular cartilages, where, to the naked eye, they appear to end. Microscopically, however, the synovial membrane can be traced for a short distance over the extreme lateral part of the articular cartilage. In the same manner, such intra-articular fibrocartilages as the semilunar cartilages in the knee-joint are not completely clothed by synovial membrane, as was at one time thought, for the membrane strays for a short distance

* Read in opening a discussion in the Section of Anatomy and Anthropology at the Annual Meeting of the British Medical Association, Aberdeen, 1939. 